
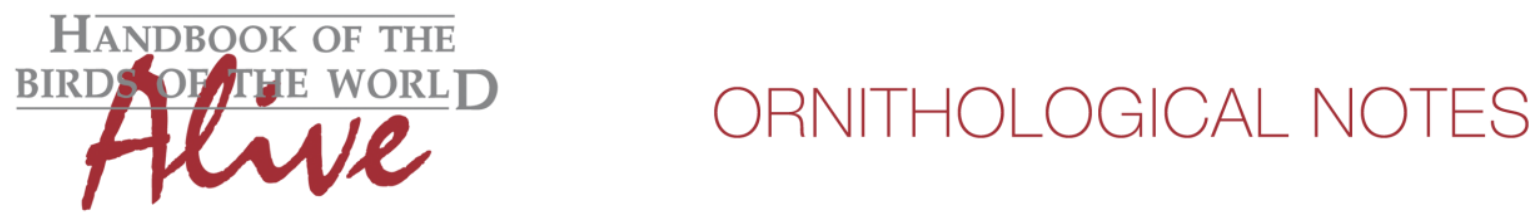

\title{
Notes on the vocalizations of Boat-billed Flycatcher (Megarynchus pitangua)
}

Peter Boesman

In the following we briefly analyze and compare voice of the different races of Boat-billed Flycatcher (Megarynchus pitangua). We also try to quantify the extent of any vocal differences using the criteria proposed by Tobias et al. (2010), as a support for taxonomic review. We have made use of sound recordings available on-line from Xeno Canto (XC).

\section{Day-time 'rattle call'}

W Mexico (M. p. tardiusculus: no recordings, M. p. caniceps: 2 recordings)

A series of burry downslurred notes more or less interconnected, ending with a longer emphasized burry note.

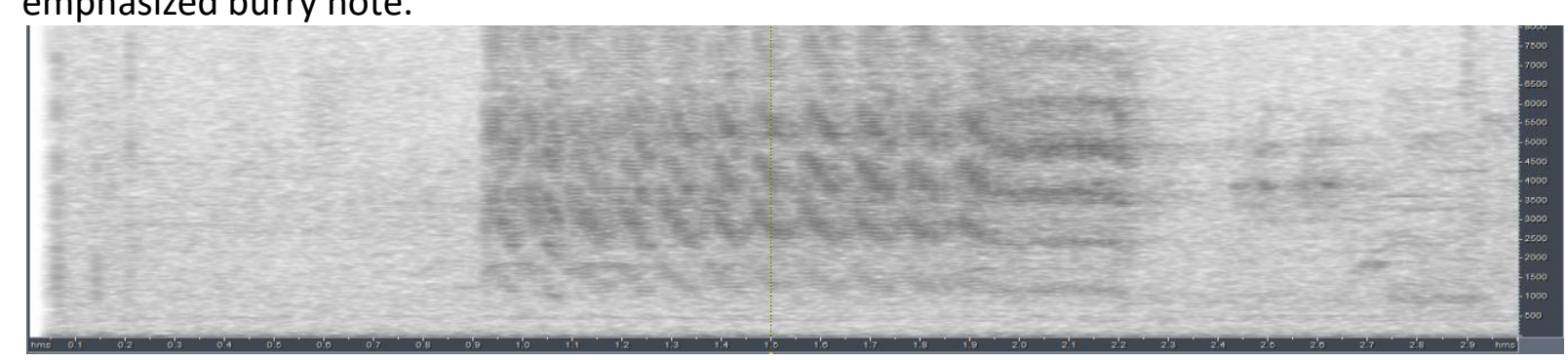

Measurements:

length

\# of notes

note length

$\min$ freq

max freq
$0.6-1.32 \mathrm{~s}$

6-12

$0.07-0.09 \mathrm{~s}$

$900-1000 \mathrm{~Hz}$

$1800-2000 \mathrm{~Hz}$

E Mexico, SW Mexico and Central America (M. p. mexicanus, M. p. deserticola: no recordings) $(n=9)$

A flat rattled series of notes, ending with a longer emphasized note

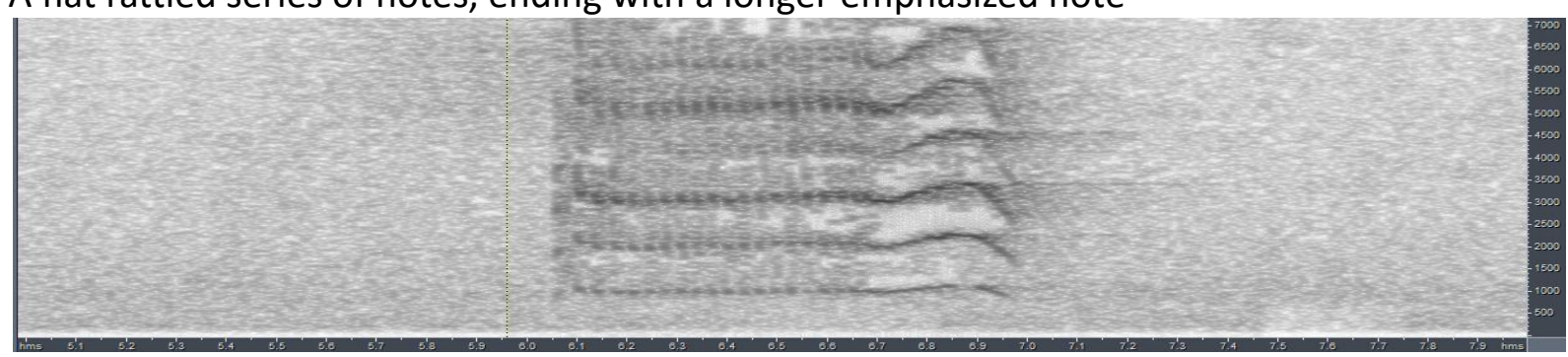

Measurements:

length

\# of notes

note length

min freq

max freq
$0.6-1.26 \mathrm{~s}$

11-35

$0.02-0.045 \mathrm{~s}$

$700-920 \mathrm{~Hz}$

$1140-1500 \mathrm{~Hz}$ 

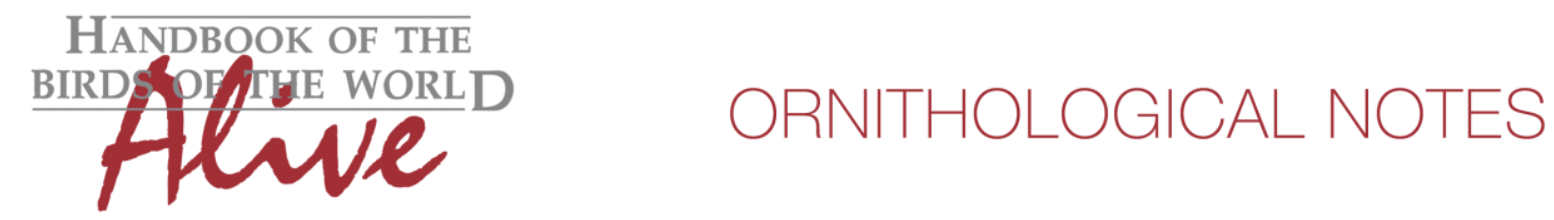

W Ecuador and NW Peru (M. p. chrysogaster)

A short series of burry downslurred notes, ending with a longer note (quite similar to birds of W Mexico).

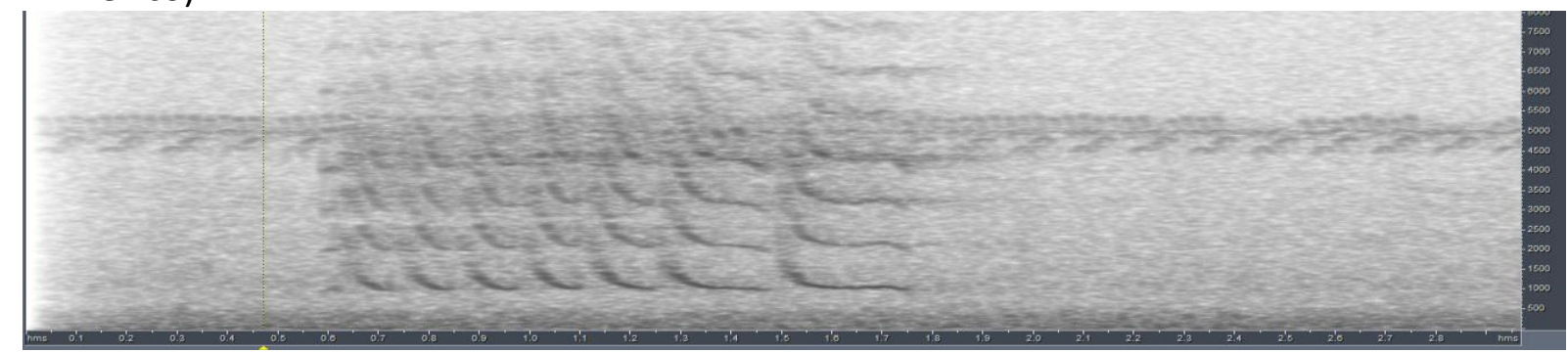

Measurements:

length

$0.65-1.2 \mathrm{~s}$

\# of notes

5-8

note length

$0.09-0.11 \mathrm{~s}$

$\min$ freq

$700-1070 \mathrm{~Hz}$

max freq

$2000-2600 \mathrm{~Hz}$

\section{Rest of S America (pitangua)}

A very distinctive series of alternations of a very burry nasal note and a more whistled nasal note (the latter flat or upslurred), without an obvious long note at the end. Structurally quite different from all above races.

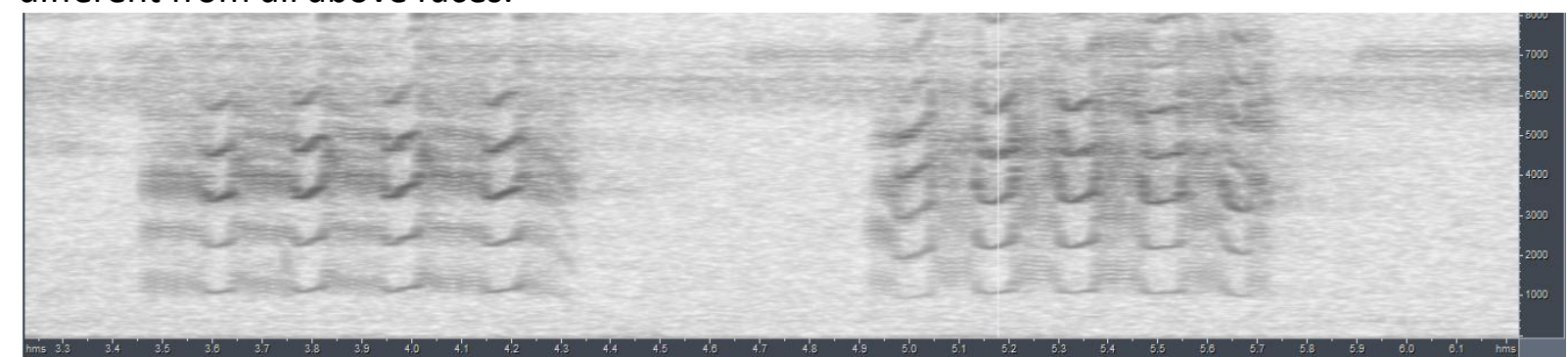

Measurements:

length

\# of notes

note length

$\min$ freq

max freq

\section{$0.7-1.4 \mathrm{~s}$}

7-11

$0.12-0.2 \mathrm{~s}$

$750-1000 \mathrm{~Hz}$

$1800-2000 \mathrm{~Hz}$

\section{Dawn song}

There aren't that many recordings available (except for pitangua), but it would seem that there are no clear differences in dawn song.

Dawn song is either a repeated strident note "kirr" (several oscillations on a sonogram), or the same note followed by a lower pitched rising rattle that ends with an emphasized note "kirr..krrr-wheet.....kirr..krrr-wheet.....".

The only difference we have noted is that the 2 available examples of mexicanus are of the more elaborated dawn song "kir..krrr-wheet", while in chrysogaster and pitangua we have only found 2 examples of this longer song (out of 14 examples), the rest being the short dawn song. 

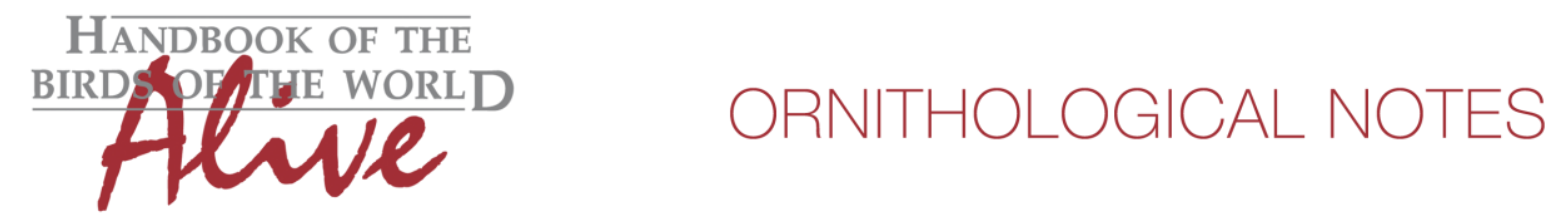

\section{Other vocalizations}

All races have additional calls, given during interaction or excitement. We haven't looked into these.

\section{Discussion}

From the above, it would seem that the common day-time call is more distinctive than the dawn song (something we have already noted with several Tyrant Flycatchers, e.g. Zimmerius genus and some Myiarchus flycatchers).

Structurally, the day-time call of M.p.pitangua is very different, but quantification of this difference is not straightforward: There is the absence of a long end note (e.g. ratio last/center note) (score 2-3). If we consider the alternating notes as two distinct notes, than the alternations are unique, if we consider it as a repeated single complex note, then the note length is far longer than any other group. In both cases, this would lead to a score of 23. All in all, applying Tobias criteria, this would lead to a total vocal score of about 5 .

Of the remaining groups, M.p. mexicanus stands apart, with higher number of notes, shorter note length and faster pace, all scoring 2-3, leading to a total score of about 5.

Despite the geographical distance, NW Mexican and Tumbes birds are less different. Apart from the more burry notes in NW Mexico birds, not much differences can be noted (on the small number of samples, and based solely on the day-time rattle-call).

This note was finalized on 19th August 2015, using sound recordings available on-line at that moment. We would like to thank in particular the many sound recordists who placed their recordings for this species on XC.

\section{References}

Tobias, J.A., Seddon, N., Spottiswoode, C.N., Pilgrim, J.D., Fishpool, L.D.C. \& Collar, N.J. (2010). Quantitative criteria for species delimitation. Ibis 152(4): 724-746.

\section{Recommended citation}

Boesman, P. (2016). Notes on the vocalizations of Boat-billed Flycatcher (Megarynchus pitangua). HBW Alive Ornithological Note 140. In: Handbook of the Birds of the World Alive. Lynx Edicions, Barcelona. (retrieved from http://www.hbw.com/node/932064 on 10 August 2016). 